\title{
Mutagenic synergism detected between 1,2-dibromoethane and $X$ rays in the stamen hairs of Tradescantia clone BNL 4430
}

\author{
Ling Zhi Xiao and Sadao Ichikawa* \\ Laboratory of Genetics, Department of Regulation Biology, Faculty of Science, \\ Saitama University, Urawa 338-8570, Japan
}

(Received 22 January 1998, accepted 5 June 1998)

\begin{abstract}
Mutagenic interaction between 1,2-dibromoethane (EDB) and X rays was studied in the stamen hairs of Tradescantia clone BNL 4430, a blue/pink heterozygote. The young inflorescence-bearing shoots with roots of this clone cultivated in a nutrient solution circulating growth chamber were used as the tester plants. EDB is a promutagen and also a bifunctional alkylating agent with a high Swain-Scott substrate constant, but is thought to react probably via $\mathrm{SN}_{1}$ mechanism. After confirming the dose-dependent mutagenicities of aqueous solutions of EDB for the first time in Tradescantia stamen hairs, a combined treatment with EDB and X rays was conducted, exposing acutely to $578 \mathrm{mGy} \mathrm{X}$ rays at the midpoint of $66.5 \mathrm{mM}$ EDB treatment for $4 \mathrm{~h}$. The induced somatic mutation frequency determined after the combined treatment was significantly higher (at $0.1 \%$ level) than that expected from the additive effects of EDB and X rays, showing that EDB and X rays acted obviously synergistically. The confirmation of the mutagenic synergism between EDB and X rays is reported here for the first time, although a likelihood of synergistic effects of EDB with ${ }^{3} \mathrm{H}$ beta rays has been suggested earlier.
\end{abstract}

\section{INTRODUCTION}

Surveys of mutagenic interactions among different mutagens and promutagens are urgently needed because various kinds of mutagens and promutagens coexist in our environment. In fact, mutagenic synergisms among four monofunctional alkylating agents and X rays have clearly been detected using Tradescantia stamen-hair system, i.e., between ethyl methanesulfonate (EMS) and X rays (Cebulska-Wasilewska et al., 1981; Shima and Ichikawa, 1994), methyl methanesulfonate (MMS) and X rays (Ichikawa, 1992; Ichikawa et al., 1993; Shima and Ichikawa, 1994), EMS and MMS (Shima and Ichikawa, 1994), dimethyl sulfate (DMS) and $X$ rays (Shima and Ichikawa, 1995), and $N$-ethyl- $N$-nitrosourea (ENU) and X rays (Shima and Ichikawa, 1997). Different patterns of such synergisms have also been reported (Shima and Ichikawa, 1994, 1995, 1997).

Mutagenic synergisms with $\mathrm{X}$ rays have also been detected for three promutagens, maleic hydrazide (MH) (Xiao and Ichikawa, 1995), o-phenylenediamine (PDA) and $\mathrm{N}$ nitrosodimethylamine (DMN) (Xiao and Ichikawa, 1998), by exposing Tradescantia stamen hairs to $\mathrm{X}$ rays before 4$\mathrm{h}$ MH, PDA or DMN treatments. X-raying during the 4-h

\footnotetext{
* Corresponding author.
}

DMN treatments also resulted in synergistic effects (Xiao and Ichikawa, 1998). On the other hand, mutagenic antagonisms have been observed between $\mathrm{X}$ rays and any of these promutagens by delivering $\mathrm{X}$ rays after 4-h MH, PDA or DMN treatments (Xiao and Ichikawa, 1995, 1998) and during the 4-h MH treatments (Xiao and Ichikawa, 1995). The involvement of peroxidase in activating $\mathrm{MH}$ into a mutagen in the floral tissues has been confirmed, and the occurrences of such synergisms and antagonisms between $\mathrm{MH}$ and $\mathrm{X}$ rays have clearly been related to increases and decreases, respectively, in peroxidase activity (Xiao and Ichikawa, 1996).

For evaluating real risks of environmental mutagens and promutagens, therefore, occurrences of such mutagenic interactions must be taken into consideration. Mutagenic synergisms have most serious implications for current risk evaluations of individual mutagenic agents, and are considered to occur between different agents which have some interrelated or at least partly common mechanisms of action, while no synergism would occur between different agents which cause entirely different damages on DNA (Shima and Ichikawa, 1994).

In the present study, mutagenic interaction of 1,2dibromoethane (EDB) with X rays was studied in Tradescantia stamen hairs. Also, the mutagenicities of aqueous solutions of EDB were studied for the first time in the sta- 
men hairs, although those of gaseous EDB have been reported (Sparrow et al., 1974; Nauman et al., 1976, 1979). EDB is a promutagen and also a bifunctional alkylating agent with a high Swain-Scott substrate constant $(s)$ of 1.2 (Ehrenberg et al., 1974), but is thought to react probably via $\mathrm{SN}_{1}$ mechanism with a relatively high $\mathrm{O}^{6} / \mathrm{N}-7$ alkylation ratio of guanine (Nauman et al., 1976).

\section{MATERIALS AND METHODS}

Tester plants used. Young inflorescence-bearing shoots with roots of Tradescantia clone BNL 4430 as described earlier (Shima and Ichikawa, 1994; Ichikawa et al., 1995; Shima et al., 1997) were used as the tester plants in the present study. This clone is a diploid hybrid $(2 \mathrm{n}=12)$ between a blue-flowered T. hirsutiflora Bush and a pink-flowered T. subacaulis Bush (Emmerling-Thompson and Nawrocky, 1980), thus is a blue/pink heterozygote. This clone has been frequently used for somatic mutation assays in the stamen hairs as reviewed earlier (Schairer and Sautkulis, 1982; Ichikawa, 1992), and has been shown to be more sensitive to alkylating agents than other clones while its radiosensitivity is comparable to others (Sparrow et al., 1974; Nauman et al., 1976; Ichikawa et al., 1993).

Cultivating conditions. The young inflorescence-bearing shoots with roots were cultivated in the nutrient solution circulating (NSC) growth chamber described in detail by Shima et al. (1997). The environmental conditions in the NSC growth chamber were $22.0 \pm 0.5^{\circ} \mathrm{C}$ during the 16 $\mathrm{h}$ day with a light intensity of 7,500 lux from white fluorescent tubes and $20.0 \pm 0.5^{\circ} \mathrm{C}$ at night. The nutrient solution used was a 1/2,500 Hyponex solution.

EDB treatments. Young inflorescences just before initiating flowering were treated with 33.3, 53.2, 66.5 and 133 mM EDB (CAS no. 106-93-4; Wako Pure Chem. Ind., Ltd.) dissolved in DMSO (the final DMSO concentration was $6.25 \%$ ), for $4 \mathrm{~h}$ at $23.0 \pm 0.5^{\circ} \mathrm{C}$. The control inflorescences were treated with $6.25 \%$ DMSO. The methods used for the treatments have been described elsewhere (Ichikawa and Takahashi, 1978; Ichikawa et al., 1990, 1993; SandaKamigawara et al., 1991; Ichikawa, 1992; Shima and Ichikawa, 1994; Xiao and Ichikawa, 1995). Immediately after the treatments, inflorescences were washed with tap water for 2 min.

Combined treatments with EDB and $\mathrm{X}$ rays. Young inflorescences were treated with $66.5 \mathrm{mM}$ EDB for $4 \mathrm{~h}$ and were exposed acutely to $\mathrm{X}$ rays $2 \mathrm{~h}$ before starting, at the midpoint of ( $2 \mathrm{~h}$ after starting), or $20 \mathrm{~h}$ after completing the EDB treatments. The X-ray treatments were conducted acutely using a Hitachi MBR-1505R X-ray generator at $150 \mathrm{kVp}$ and $4 \mathrm{~mA}$ with a $0.5 \mathrm{~mm} \mathrm{Al}+0.1 \mathrm{~mm} \mathrm{Cu}$ filter at $23.0 \pm 0.5^{\circ} \mathrm{C}$. The target distance was $450 \mathrm{~mm}$.
The exposures were measured simultaneously with thermoluminescence dosimeter (TLD) elements (National UD170L; six elements per treatment) and with a thermoluminescence reader (National UD-502B). The exposure data obtained in $\mathrm{R}$ were converted into absorbed doses in Gy with a converting factor of $9.57 \times 10^{-3}$ (i.e., $1 \mathrm{R}=9.57 \mathrm{mGy}$ ). The X-ray doses applied were mostly about 500 to $600 \mathrm{mGy}$.

Scoring mutations. The methods used for scoring pink mutations in the stamen hairs were identical to those described elsewhere in detail (Ichikawa, 1992). Based on the scorings of the numbers of hairs and pink mutant events (PMEs) as well as the average number of cells per hair, daily somatic mutation frequencies as the numbers of PMEs per $10^{4}$ hair-cell divisions were calculated. The data were pooled for the 4-day peak period of mutation frequency for each treatment as in earlier studies (Ichikawa et al., 1993; Shima and Ichikawa, 1994, 1995, 1997; Xiao and Ichikawa, 1995, 1998).

Statistical examination. Chi-square test was used for determining the occurrence of a synergistic or an antagonistic effect, examining whether or not an induced mutation frequency obtained after a combined treatment with EDB and $\mathrm{X}$ rays was significantly higher or lower than that expected from an additive effect of EDB and $\mathrm{X}$ rays. The mutation frequency expected to be induced by the X-ray dose applied in a combined treatment was calculated using the equation, $y=49.734 x^{1.342}$, of the dose-response curve for $\mathrm{X}$ rays determined earlier in a series of related experiments (Xiao and Ichikawa, 1998), since it was difficult to apply exactly the same X-ray dose in the combined treatment and its positive control treated with $\mathrm{X}$ rays alone (Shima and Ichikawa, 1995; Xiao and Ichikawa, 1998).

\section{RESULTS AND DISCUSSION}

EDB-induced mutation frequencies. Treatments with 33.3 to $133 \mathrm{mM}$ EDB for $4 \mathrm{~h}$ were conducted, but EDB was not dissolved completely at these concentrations, EDB dissolved in DMSO being separated again and coming to the surface after diluted by distilled water. Therefore, each EDB solution was mixed well just before treating each inflorescence. The EDB treatments showed severe toxicities, decreasing greatly the number of flowers opened especially at 66.5 and $133 \mathrm{mM}$ (see the next section). Nevertheless, clearly dose-dependent responses were observed for the first time with aqueous solutions of EDB, and the mutation frequencies per $10^{4}$ hair-cell divisions obtained after these EDB treatments are presented in Table 1. The mutation frequencies in the four controls treated with $6.25 \%$ DMSO were comparable to those in untreated shoots with roots of the same clone (Ichikawa et al., 1995; Shima et al., 1997). When the induced mutation frequencies after subtracting each control frequency 
Table 1. Somatic pink mutation frequencies induced by 33.3 to $133 \mathrm{mM}$ EDB treatments for $4 \mathrm{~h}$ in the stamen hairs of Tradescantia clone BNL 4430

\begin{tabular}{|c|c|c|c|c|c|}
\hline $\begin{array}{l}\text { EDB } \\
\text { dose } \\
(\mathrm{mM})\end{array}$ & $\begin{array}{l}\text { No. of } \\
\text { hairs } \\
\text { scored }\end{array}$ & $\begin{array}{l}\text { No. of } \\
\text { PMEs }^{a} \\
\text { scored }\end{array}$ & $\begin{array}{l}\text { Average } \\
\text { no. of cells } \\
\text { /hair }\end{array}$ & $\begin{array}{l}\text { No. of PMEs } \\
/ 10^{4} \text { cell divi- } \\
\text { sions }( \pm \mathrm{SE})\end{array}$ & $\begin{array}{l}\text { Minus } \\
\text { control } \\
( \pm \mathrm{SE})\end{array}$ \\
\hline \multicolumn{6}{|c|}{ Experiment 1} \\
\hline 0 & 25,080 & 83 & 24.09 & $1.43 \pm 0.16$ & $\longrightarrow$ \\
\hline 66.5 & 5,401 & 93 & 21.71 & $8.31 \pm 0.86$ & $6.88 \pm 0.88$ \\
\hline \multicolumn{6}{|c|}{ Experiment 2} \\
\hline 0 & 16,449 & 60 & 24.16 & $1.57 \pm 0.20$ & \\
\hline 66.5 & 5,288 & 90 & 20.94 & $8.54 \pm 0.90$ & $6.96 \pm 0.92$ \\
\hline \multicolumn{6}{|c|}{ Experiment 3} \\
\hline 0 & 23,244 & 91 & 24.22 & $1.69 \pm 0.18$ & \\
\hline 33.3 & 15,854 & 150 & 20.98 & $4.74 \pm 0.39$ & $3.05 \pm 0.43$ \\
\hline 133 & 5,544 & 168 & 20.11 & $15.9 \pm 1.2$ & $14.2 \pm 1.2$ \\
\hline \multicolumn{6}{|c|}{ Experiment 4} \\
\hline 0 & 9,288 & 35 & 23.73 & $1.66 \pm 0.28$ & $\longrightarrow$ \\
\hline 53.2 & 7,608 & 110 & 21.22 & $7.15 \pm 0.68$ & $5.49 \pm 0.74$ \\
\hline
\end{tabular}

${ }^{a}$ Pink mutant events.

are plotted against EDB concentration on a log-log graph, a dose-response curve as shown in Figure 1 is obtained. The slope value of this regression line is 1.103 , being obviously smaller than 1.373 for gaseous EDB determined earlier in the same clone (Sparrow et al., 1974), and also than 1.295 for PDA (Xiao and Ichikawa, 1998), and those for X rays determined in the same shoots with roots, i.e., 1.252 (Shima and Ichikawa, 1994), 1.314 (Shima and Ichikawa,

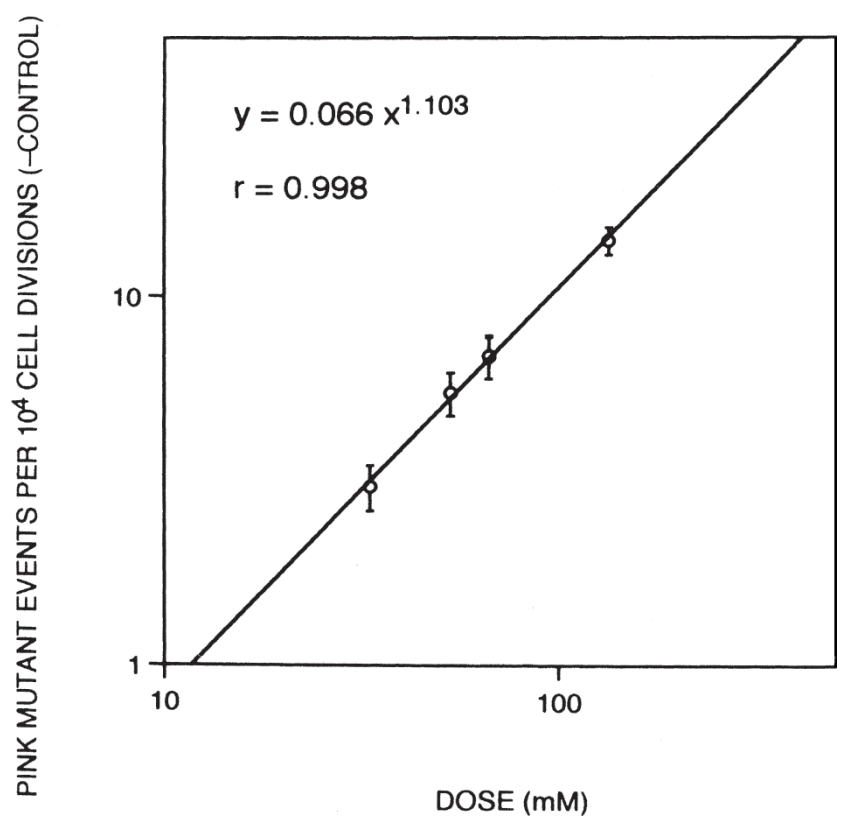

Fig. 1. The dose-response curve for EDB-induced somatic mutation frequencies in the stamen hairs of Tradescantia clone BNL 4430. The best-fit regression line determined by the least squares method, the equation representing it, correlation coefficient, and standard errors for the points plotted are drawn.
1995), 1.342 (Xiao and Ichikawa, 1998), and 1.390 (Xiao and Ichikawa, 1995). The slope value was somewhat larger, however, than 1.041 for DMN (Xiao and Ichikawa, 1998). The small slope value is thought to be due to that EDB was less completely dissolved at higher concentrations.

EDB produced many 'leaky-like' hair cells with intermediate color tints as DMN did in our earlier study (Xiao and Ichikawa, 1998), especially on post-treatment days 7 to 10 , about two days later than with DMN. The majority of such 'leaky-like' cells were, however, considered to be the results of physiological disturbances, not being genuine leaky mutations, based on the relationship between posttreatment day and the position in hairs where induced mutant cells could appear (Ichikawa, 1994; SandaKamigawara et al., 1995). Therefore, a special care had to be taken to distinguish 'leaky-like' cells from genuine leaky mutations, noting the day-position relationship.

Synergistic effect of EDB and $X$ rays. Due to the severe toxicity of EDB to the inflorescences treated, the number of flowers opened decreased greatly (see below), and thus only one combined treatment was successful, i.e., exposing acutely to $578 \mathrm{mGy} \mathrm{X}$ rays at the midpoint of 66.5 mM EDB treatment for $4 \mathrm{~h}$. This combined treatment was conducted together with Experiment 2 in Table 1, and the data obtained are presented in Table 2. It should be noted that the numbers of inflorescences treated with $\mathrm{X}$ rays alone, EDB alone and the both were 19, 35 and 31, respectively, but the total numbers of flowers opened (during the 4-day peak period of mutation frequency) after treatments with EDB alone and EDB plus X rays were only about two fifths and one fourth, respectively, of that after X-ray treatment alone (see the numbers of hairs scored shown in Table 2). The mutation frequency induced by $555 \mathrm{mGy} \mathrm{X}$ rays 
Table 2. Synergistic effect in inducing somatic mutations in the stamen hairs of Tradescantia clone BNL 4430 detected by exposing to $\mathrm{X}$ rays at the midpoint of 4-h EDB treatment

\begin{tabular}{ccccccccc}
\hline \hline $\begin{array}{c}\text { EDB } \\
\text { dose } \\
(\mathrm{mM})\end{array}$ & $\begin{array}{c}\text { X-ray } \\
\text { dose } \\
(\mathrm{mGy})\end{array}$ & $\begin{array}{c}\text { No. of } \\
\text { hairs } \\
\text { scored }\end{array}$ & $\begin{array}{c}\text { No. of } \\
\mathrm{PMEs}^{\mathrm{a}} \\
\text { scored }\end{array}$ & $\begin{array}{c}\text { Average } \\
\text { no. of } \\
\text { cells/hair }\end{array}$ & $\begin{array}{c}\text { No. of PMEs } \\
10^{4} \text { cell divi- } \\
\text { sions }( \pm \mathrm{SE})\end{array}$ & $\begin{array}{c}\text { Minus } \\
\text { control } \\
( \pm \mathrm{SE})\end{array}$ & $\begin{array}{c}\text { Expect- } \\
\text { ed }^{\mathrm{b}}\end{array}$ & $\begin{array}{c}P \\
0\end{array}$ \\
\hline 0 & 16,449 & 60 & 24.16 & $1.57 \pm 0.20$ & - & & \\
66.5 & 0 & 5,288 & 90 & 20.94 & $8.54 \pm 0.90$ & $6.96 \pm 0.92$ & & \\
0 & 555 & 12,350 & 598 & 23.14 & $21.9 \pm 0.9$ & $20.3 \pm 0.9$ & 30.8 & $<0.001$ \\
\hline
\end{tabular}

${ }^{\text {a }}$ Pink mutant events.

${ }^{\mathrm{b}}$ Expected number of PMEs per $10^{4}$ hair-cell divisions by an additive effect. Expected value for X rays was calculated using the equation, $y=49.734 x^{1.342}$, of the dose-response curve for $\mathrm{X}$ rays determined earlier in a series of related experiments (Xiao and Ichikawa, 1998), and that for EDB was taken from the positive control.

alone fitted very well to the dose-response curve for $\mathrm{X}$ rays with the slope of 1.342 determined earlier in a series of related experiments (Xiao and Ichikawa, 1998). The induced mutation frequency obtained after the combined treatment was significantly higher (at $0.1 \%$ level) than that expected from the additive effect of EDB and $\mathrm{X}$ rays, showing that EDB and $\mathrm{X}$ rays acted obviously synergistically in inducing mutations when $\mathrm{X}$ rays were delivered at the midpoint of the EDB treatment.

Other combined treatments with EDB and $\mathrm{X}$ rays, i.e., exposing to $\mathrm{X}$ rays either $2 \mathrm{~h}$ before starting or $20 \mathrm{~h}$ after completing EDB treatments for $4 \mathrm{~h}$, were also conducted, but these two experiments were unsuccessful because of insufficient numbers of flowers opened. Although an apparent tendency of antagonistic effect was observed by Xraying $20 \mathrm{~h}$ after completing the 4 -h EDB treatment, no significant difference could be detected from the small sample sizes, thus nothing could be concluded definitely.

One may argue that similar experiments should be repeated before publishing the above results, because two out of three combined treatments with EDB and $\mathrm{X}$ rays did not yield sufficient data to give any conclusions. As stated above, the numbers of inflorescences required for conducting one set of such experiment, i.e., for the combined treatment, two positive controls and the control, are quite large because of the severe toxicity of EDB, and it takes time to prepare them. Since high degrees of reappearance of somatic mutation assays with Tradescantia stamen hairs have been demonstrated clearly (Ichikawa, 1992), especially by using young inflorescence-bearing shoots with roots of clone BNL 4430 cultivated in the NSC growth chamber (Ichikawa et al., 1995; Shima et al., 1997), it is worthy to publish the results even from a single successful set of experiment, together with the following discussion.

EDB is a promutagen and also a bifunctional alkylating agent with a high $s$ value of 1.2 (Ehrenberg et al., 1974), but reacts probably via $\mathrm{SN}_{1}$ mechanism with a relatively high $\mathrm{O}^{6} / \mathrm{N}-7$ alkylation ratio of guanine (Nauman et al., 1976). EDB has been shown to induce DNA single-strand breaks and chromosomal aberrations in barley (Ehrenberg et al., 1974). It has been demonstrated recently that the synergistic effects of four monofunctional alkylating agents (EMS, MMS, DMS, and ENU) with X rays (Shima and Ichikawa, 1994, 1995, 1997) and no synergism of another monofunctional alkylating agent, $N$-methyl- $N$-nitrosourea (MNU), with X rays (Shima and Ichikawa, 1995) do not have any clear relationships with their $s$ values (Shima and Ichikawa, 1997). It is thus thought most likely that DNA single-strand breaks produced commonly by $\mathrm{X}$ rays and alkylating agents or promutagens are the major causes of the mutagenic synergisms, as discussed earlier (Ichikawa et al., 1993; Shima and Ichikawa, 1995, 1997; Xiao and Ichikawa, 1995, 1998). The mutagenic synergism found in the present study between EDB and $\mathrm{X}$ rays when X-rayed during the EDB treatment is also considered to be mainly the results of interactions between DNA strand breaks (and the resultant chromosomal breaks) induced by $\mathrm{X}$ rays and those by EDB. A likelihood of synergistic effects of EDB with ${ }^{3} \mathrm{H}$ beta rays in Tradescantia stamen hairs has been suggested earlier (Nauman et al., 1979).

It has been shown that EDB can be converted into a mutagen via two reaction pathways, one involving a breakdown product in vitro and the other involving metabolic activation by plants, the latter being apparently energydependent as that for mammalian microsomal activation of EDB (Scott et al., 1978), although the mechanism of the activation of EDB in plant cells has not yet been fully understood. The incomplete results but showing an apparent tendency of antagonistic effect observed in the present study by exposing to $\mathrm{X}$ rays $20 \mathrm{~h}$ after the 4 -h EDB treatment may suggest that the activation of EDB might be inhibited by $\mathrm{X}$ rays delivered during the activation period of EDB, as in cases of other promutagens, $\mathrm{MH}$ (Xiao and Ichikawa, 1995, 1996), PDA and DMN (Xiao and Ichikawa, 1998).

The present study was supported in part by the Grant-in-Aid for Scientific Research (08680565) from the Ministry of Education, Science, Sports, and Culture of Japan to S.I. 


\section{REFERENCES}

Cebulska-Wasilewska, A., Leenhouts, H. P., and Chadwick, K. H. (1981) Synergism between EMS and X-rays for the induction of somatic mutations in Tradescantia. Int. J. Radiat. Biol. 40, 163-173.

Ehrenberg, L., Osterman-Golker, S., Singh, D., and Lundqvist, U. (1974) On the reaction kinetics and mutagenic activity of methylating and $\beta$-halogenoethylating gasoline additives. Radiat. Bot. 14, 185-194.

Emmerling-Thompson, M., and Nawrocky, M. M. (1980) Genetic basis for using Tradescantia clone 4430 as an environmental monitor of mutagens. J. Hered. 71, 261-265.

Ichikawa, S. (1992) Tradescantia stamen-hair system as an excellent botanical tester of mutagenicity: Its responses to ionizing radiations and chemical mutagens, and some synergistic effects found. Mutat. Res. 270, 3-22.

Ichikawa, S. (1994) Sectoring patterns of spontaneous and radiation-induced somatic pink mutations in the stamen hairs of a temperature-sensitive mutable clone of Tradescantia. Jpn. J. Genet. 69, 577-591.

Ichikawa, S., and Takahashi, C. S. (1978) Somatic mutations in Tradescantia stamen hairs exposed to ethyl methanesulfonate. Environ. Exp. Bot. 18, 19-25.

Ichikawa, S., Kanai, H., and Harada, H. (1990) Somatic mutation frequencies in Tradescantia stamen hairs treated with aqueous solutions of ethyl methanesulfonate and methyl methanesulfonate. Jpn. J. Genet. 65, 309-321.

Ichikawa, S., Yamaguchi, A., and Okumura, M. (1993) Synergistic effects of methyl methanesulfonate and $\mathrm{X}$ rays in inducing somatic mutations in the stamen hairs of Tradescantia clones, KU 27 and BNL 4430. Jpn. J. Genet. 68, 277-292.

Ichikawa, S., Shima, N., Xiao, L. Z., Matsuura-Endo, C., Harada, H., Yogo, A., and Okumura, M. (1995) Flower production, stamen-hair growth, and spontaneous and induced somatic mutation frequencies in Tradescantia cuttings and shoots with roots cultivated with nutrient solutions. Jpn. J. Genet. 70, 585-600.

Nauman, C. H., Sparrow, A. H., and Schairer, L. A. (1976) Comparative effects of ionizing radiation and two chemical mutagens on somatic mutation induction in one mutable and two non-mutable clones of Tradescantia. Mutat. Res. 38, 53-70.

Nauman, C. H., Klotz, P. J., and Schairer, L. A. (1979) Uptake of tritiated 1,2-dibromoethane by Tradescantia floral tissues: Relation to induced mutation frequency in stamen hair cells. Environ. Exp. Bot. 19, 201-215.

Sanda-Kamigawara, M., Ichikawa, S., and Watanabe, K. (1991) Spontaneous, radiation- and EMS-induced somatic pink mu- tation frequencies in the stamen hairs and petals of diploid clone of Tradescantia, KU 27. Environ. Exp. Bot. 31, 413421.

Sanda-Kamigawara, M., Tomiyama, M., and Ichikawa, S. (1995) Sectoring patterns of spontaneous and induced somatic pink mutations in the stamen hairs and petals of mutable and stable clones of Tradescantia. Jpn. J. Genet. 70, 339-353.

Schairer, L. A., and Sautkulis, R. C. (1982) Detection of ambient levels of mutagenic atmospheric pollutants with the higher plant Tradescantia. In: Environmental Mutagenesis, Carcinogenesis, and Plant Biology, vol. 2 (ed.: E. J. Klelowski, Jr.), pp. 155-194. Praeger, New York.

Scott, B. R., Sparrow, A. H., Schwemmer, S. S., and Schairer, L. A. (1978) Plant metabolic activation of 1,2-dibromoethane (EDB) to a mutagen of greater potency. Mutat. Res. 49, 203-212.

Shima, N., and Ichikawa, S. (1994) Synergisms detected among methyl methanesulfonate, ethyl methanesulfonate and X-rays in inducing somatic mutations in the stamen hairs of Tradescantia clone BNL 4430. Environ. Exp. Bot. 34, 393-408.

Shima, N., and Ichikawa, S. (1995) Mutagenic synergism detected between dimethyl sulfate and X-rays but not found between $N$-methyl- $N$-nitrosourea and X-rays in the stamen hairs of Tradescantia clone BNL 4430. Mutat. Res. 331, 79-87.

Shima, N., and Ichikawa, S. (1997) Synergistic effects of $N$-ethyl$N$-nitrosourea (an alkylating agent with a low Swain-Scott substrate constant) and X-rays in the stamen hairs of Tradescantia clone BNL 4430. Environ. Mol. Mutagen. 29, 323329.

Shima, N., Xiao, L. Z., Sakuramoto, F., and Ichikawa, S. (1997) Young inflorescence-bearing shoots with roots of Tradescantia clone BNL 4430 cultivated in nutrient solution circulating systems: An alternative to potted plants and cuttings for mutagenicity tests. Mutat. Res. 395, 199-208.

Sparrow, A. H., Schairer, L. A., and Villalobos-Pietrini, R. (1974) Comparison of somatic mutation rates induced in Tradescantia by chemical and physical mutagens. Mutat. Res. 26, $265-276$.

Xiao, L. Z., and Ichikawa, S. (1995) Mutagenic interactions between maleic hydrazide and $\mathrm{X}$ rays in the stamen hairs of Tradescantia clone BNL 4430. Jpn. J. Genet. 70, 473-485.

Xiao, L. Z., and Ichikawa, S. (1996) Peroxidase activities in the floral tissues of Tradescantia clone BNL 4430 treated with maleic hydrazide alone, $\mathrm{X}$ rays alone, or in combinations. Genes Genet. Syst. 71, 151-157.

Xiao, L. Z., and Ichikawa, S. (1998) Mutagenic interactions between X-rays and two promutagens, $o$-phenylenediamine and $N$-nitrosodimethylamine, in the stamen hairs of Tradescantia clone BNL 4430. Mutat. Res. 413, 177-186. 